\title{
Apreciação econômica da terminação em confinamento de novilhos Red Angus superjovens abatidos com diferentes pesos
}

\author{
João Restle ${ }^{1}$, Paulo Santana Pacheco ${ }^{2}$, Eduardo Castro da Costa ${ }^{3}$, Aline Kellermann de \\ Freitas $^{4}$, Fabiano Nunes Vaz $^{5}$, Ivan Luiz Brondani ${ }^{6}$, Juliano José de Resende Fernandes ${ }^{7}$
}

\footnotetext{
1 Pesquisador Visitante/CNPq - DPA/UFG.

2 Doutorando PPGCA - UFG. Bolsista CAPES

${ }^{3}$ Doutorando CEPAN - UFRGS.

${ }^{4}$ Mestranda PPGCA - UFG. Bolsista CNPq.

${ }^{5}$ Doutorando CEPAN - UFRGS. Bolsista CNPq

${ }^{6}$ Departamento de Zootecnia - UFSM.

${ }^{7}$ Departamento de Produção Animal - UFG.
}

RESUMO - Objetivou-se com este estudo avaliar economicamente a terminação em confinamento de novilhos Red Angus superjovens alimentados até atingirem os pesos de abate pretendidos de 340, 370, 400 e $430 \mathrm{~kg}$ (pesos reais obtidos: 340, 373, 401 e $434 \mathrm{~kg}$ ). O número de dias necessários para atingir os respectivos pesos foi de 114, 144, 168 e 209 dias aos 12, 13 , 14 e 15 meses de idade. Os animais foram alimentados com dieta contendo 13,26\% de PB e relação volumoso (silagem de milho):concentrado de 56,21:43,79 na MS. Na formação e condução da lavoura para produção de volumoso, as operações mais representativas do custo total/ha foram, em ordem decrescente, adubação de plantio (21,21\%), adubação de cobertura $(12,86 \%)$, sementes $(11,40 \%)$ e controle de plantas daninhas $(5,78 \%)$ e de pragas $(4,52 \%)$. A alimentação (volumoso mais concentrado) foi o componente de custo mais representativo (média de $77,2 \%$ ) se desconsiderado o custo de compra do animal. Da alimentação, o concentrado foi o componente mais oneroso (58,3\%). O custo/kg de ganho de peso incrementou linearmente com o aumento no peso de abate, sendo de 1,94; 2,06; 2,15 e 2,34 R\$/kg, respectivamente, para os pesos de abate de 340, 373, 401 e $434 \mathrm{~kg}$. O incremento no peso de abate de 340 para $434 \mathrm{~kg}$ reduziu a lucratividade da terminação em confinamento de novilhos Red Angus superjovens.

Palavras-chave: custo de alimentação, custo de produção, custo do confinamento, idade de abate, sistema de terminação

\section{Economic evaluation of feedlot finished Red Angus young steers slaughtered with different weights}

\begin{abstract}
The objective of this experiment was to conduct an economic evaluation of feedlot finished Red Angus young steers fed to reach slaughter weights (SW) of 340, 370, 400 and $430 \mathrm{~kg}$ (actual SW of: 340, 373, 401 and $434 \mathrm{~kg}$ ). Animals spent 114, 144, 168 and 209 days to reach the target SW at 12, 13, 14 and 15 months of age, respectively. Animals were fed a diet containing $13.26 \%$ crude protein and a forage (corn silage) to concentrate ratio of 56:44 (dry matter basis). The most representative operational costs (total costs/ha) for crop establishment and management were: crop fertilization (21.21\%), top spreading fertilization (12.86\%), seeds (11.40\%), and weeds $(5.78 \%)$ and insect control $(4.52 \%)$. Feed (forage plus concentrate) represented $77.2 \%$ of the production cost when animal acquisition was not included in the calculation with concentrate accounting for $58.3 \%$ of these costs. The cost $/ \mathrm{kg}$ of weight gain increased linearly from 1.94 to $2.34 \mathrm{R} \$ / \mathrm{kg}$ when SW was increased from 340 to $434 \mathrm{~kg}$. Increasing SW from 340 to $434 \mathrm{~kg}$ reduced the profitability of feedlot finished Red Angus young steers.
\end{abstract}

Key Words: feeding cost, feedlot cost, finishing system, production cost, slaughter age

\section{Introdução}

A administração dos custos de produção é essencial em sistemas de produção de bovinos de corte, não só para auxiliar no processo de tomada de decisão como também para manter o pecuarista no agronegócio da carne bovina.

Este enfoque é especialmente importante quando o sistema de produção é intensificado, como por exemplo, para a produção de novilhos superjovens abatidos com 12 a 16 meses de idade com peso de carcaça e grau de acabamento adequados às exigências do mercado.

Esta intensificação do sistema de produção geralmente resulta em maiores investimentos e em maiores riscos, pois compreende a combinação de dois segmentos: eficiência agrícola para confecção de volumoso de qualidade e eficiência técnica para produção de carne, que engloba os fatores 
genético e nutricional. Brisolara (2001) e Vaz et al. (2003) afirmaram que, na estratégia de comercialização, devem ser considerados a época planejada para a venda, o peso de abate e o grau de acabamento pretendido, fatores estreitamente relacionados à rentabilidade do processo produtivo.

Na terminação de bovinos de corte em confinamento, a alimentação é o componente mais expressivo, pois supera $70 \%$ do custo de produção total, quando desconsiderado o valor de compra do animal (Pacheco et al., 2006). Assim, a busca por maior lucratividade deve enfocar principalmente a redução no custo com alimentação, principalmente o concentrado da dieta, fração mais onerosa que o volumoso. Alternativas viáveis seriam a produção de volumoso de qualidade, representada pela maior participação de grãos na massa ensilada, e/ou a aquisição estratégica dos ingredientes do concentrado, aproveitando preços favoráveis de acordo com a época do ano e com a região (Vaz et al., 2000).

Outro aspecto importante estaria relacionado ao potencial genético dos animais para precocidade, especificamente deposição de gordura e conversão alimentar, que estão diretamente relacionados ao tempo de permanência em confinamento. Esses dois fatores refletem na eficiência de transformar alimento consumido em ganho de peso e, portanto, no custo por kg de ganho de peso. Avaliando o desempenho em confinamento e as características da carcaça dos mesmos animais utilizados neste estudo, Costa et al. (2002 a,b) verificaram que o maior período de alimentação e, conseqüentemente, o maior peso de abate, piorou a conversão alimentar, tanto de MS como de PB e energia digestível, e ainda ocasionou incremento linear na espessura de gordura subcutânea. No entanto, resta avaliar a relação entre a resposta biológica e a resposta econômica.

Portanto, objetivou-se com este estudo avaliar economicamente a terminação em confinamento de novilhos Red Angus superjovens alimentados até atingirem os pesos de abate de 340, 373, 401 e $434 \mathrm{~kg}$.

\section{Material e Métodos}

O experimento foi conduzido no Setor de Bovinocultura de Corte do Departamento de Zootecnia da Universidade Federal de Santa Maria, em Santa Maria - RS, localizado na Depressão Central, a 153 m de altitude. Segundo classificação de Köppen, a região apresenta clima subtropical úmido (cfa) (Moreno, 1961).

Foram utilizados 24 bezerros Aberdeen Angus, variedade Red, com 8 meses de idade, 189,1 $\pm 1,78$ kg de PV inicial e estado corporal médio de 2,32 pontos (escala de 1 a 5, em que 1 = muito magro; 3 = médio e 5 = muito gordo). Os animais foram provenientes de um mesmo rebanho e desmamados aos 3 meses de idade. Aos 3 meses de idade (quando foram castrados), os animais foram mantidos em condições de campo nativo melhorado e receberam como suplemento diário farelo de arroz integral em quantidade correspondente a $1,0 \%$ do PV.

O desempenho dos animais em confinamento foi avaliado segundo os diferentes pesos de abate pré-determinados de 340, 370, 400 e $430 \mathrm{~kg}$, porém, os pesos reais obtidos foram 340, 373, 401 e $434 \mathrm{~kg}$. A dieta foi formulada segundo recomendações do NRC (1984) objetivando ganho de peso de 1,2 kg/animal/dia, estimando-se consumo diário de 2,5 kg de MS/100 kg PV. Foi utilizada relação volumoso:concentrado de 56,21:43,79 na MS. A composição média da dieta foi de 13,26\% de PB; 2,71 Mcal de ED/kg MS; 2,25 Mcal de EM/kg MS; 1,38 Mcal de EL de mantença/ kg MS; 0,80 Mcal de EL de ganho/kg MS; 52,50\% de FDN e 33,60\% de FDA. As estimativas de consumo de EM, EL de mantença e EL de ganho foram feitas a partir das equações sugeridas pelo NRC (1984).

O concentrado foi composto de farelo de soja, casca do grão de soja, farelo de arroz integral, calcário calcítico, sal comum ( $\mathrm{NaCl}$ ) e ionóforo (monensina sódica-Rumensin ${ }^{\circledR}$ ), em porcentagens que variaram de acordo com o período de alimentação. Maiores detalhes sobre o manejo da alimentação e o desempenho dos animais durante o período de confinamento constam em Costa et al. (2002 a).

O cálculo do custo representado pelas instalações do confinamento experimental foi realizado considerando para o curral de confinamento: cochos e bebedouros de concreto, piso de concreto armado, cobertura para cochos e corredor central (R\$140,00/animal); um centro de manejo (R\$ 40,00/animal); dois galpões $10 \times 15 \mathrm{~m}$ (um para armazenamento dos ingredientes do concentrado e outro para máquinas e implementos) (R\$ 60,00/animal); rede elétrica (R\$12,00/animal); e sistemas de captação de água e de captação e decantação de resíduos (chorume) (R \$10,00/animal), totalizando R \$262,00/animal, o qual foi amortizado em dez anos, chegando-se ao valor final de R\$ 0,05/animal/dia.

Foram avaliados: A - o custo com volumoso, R\$ (de acordo com o custo por kg de MS); B - o custo com concentrado, R\$ (de acordo com o custo por kg de MS); C - o custo com confecção do concentrado, R\$ (incluindo misturador, mão-de-obra, equipamentos de segurança, energia elétrica e outras ferramentas); D - o custo com fornecimento da alimentação, R\$ (incluindo trator, vagão forrageiro e mão-de-obra); E - o custo com instalações do confinamento, R\$; F - o custo com controle sanitário, R\$ 
(incluindo produto à base de ivermectina e mão-de-obra); G - o custo com compra do animal, R\$; o custo subtotal 1, $\mathrm{R} \$=\mathrm{A}+\mathrm{B}+\mathrm{C}+\mathrm{D}+\mathrm{E}+\mathrm{F}+\mathrm{G} ; \mathrm{H}$ - o custo de oportunidade da terra (durante o confinamento), $\mathrm{R} \$$ (custo por ha/dia* dias de confinamento * área necessária por animal confinado, ha); I - o custo de oportunidade do capital investido (durante o confinamento), R\$ [(custo subtotal $1-\mathrm{A}$ ) * taxa de juros média diária da poupança * dias de confinamento)]; o custo subtotal 2, R\$ = H + I; custo total, R \$ (custo subtotal 1 + custo subtotal 2); o custo por kg de ganho de peso, $\mathrm{R} \$ / \mathrm{kg}$ [(custo total - custo de compra do animal)/ganho de peso total na terminação (kg)]; a receita bruta com venda do animal gordo, $\mathrm{R} \$$; a receita bruta com transferência, $\mathrm{R} \$$ [(peso inicial * R \$ por kg vivo de boi gordo) - (peso inicial * R \$ por kg vivo de boi magro)] (Restle et al., 2000a); a receita líquida total, R\$ (receita bruta com venda do animal gordo - custo total); a lucratividade total, \% (receita líquida total/ receita bruta com venda do animal gordo $* 100$ ); a lucratividade mensal durante período de confinamento, \% [receita líquida total / (dias de confinamento/30)]; a lucratividade mensal durante período de lavoura mais confinamento, \% [receita líquida total / (dias do plantio até venda dos animais/30)]; a lucratividade mensal para 12 meses, \% [(período de lavoura + confinamento, meses * lucratividade mensal durante período de lavoura mais confinamento)/12]; e o ganho de peso necessário para cobrir o custo de cada kg de ganho de peso (custo por kg de ganho de peso/R \$ por kg vivo de boi gordo).

Neste estudo considerou-se o kg vivo do boi magro = $\mathrm{R} \$ 1,80$; o kg vivo do boi gordo = R 2,20 ; a taxa de juros média da poupança $=6,0 \%$ ao ano ( $0,50 \%$ em 30 dias); valor de 1 ha/ano = 3,0\% de R \$ 5.000,00/ha; o tempo de utilização da terra para produção de silagem $=4$ meses; $U S \$=R \$ 2,93$; e IGP-FGV (índice geral de preços da Fundação Getúlio Vargas) = valor em R $\$ / 301,540$ (base agosto 1994=100), multiplicando-se o valor do IGP-FGV obtido pelo IGP-FGV de qualquer mês e ano desejado para comparação dos valores em R\$.

Para os cálculos dos custos deste estudo, foram considerados os valores médios dos anos de 2003 e 2004 praticados no Rio Grande do Sul.

\section{Resultados e Discussão}

Para o cultivo da lavoura de milho utilizada para produção da silagem (Tabela 1), adotou-se o método de plantio direto, em seqüência ao cultivo de pastagem cultivada de inverno de aveia preta (Avena strigosa) + azevém (Lollium multiflorum).

Durante a formação e condução da lavoura, as operações mais representativas do custo total foram adubação de
Tabela 1 - Demonstração do custo de produção da silagem por ha Table 1 - Production costs of silage per ha

\begin{tabular}{|c|c|c|}
\hline \multirow[t]{2}{*}{$\begin{array}{l}\text { Operação }{ }^{1} \\
\text { Activity }\end{array}$} & \multicolumn{2}{|c|}{$\begin{array}{l}\text { Custo de produção da silagem } \\
\text { Cost of silage production }\end{array}$} \\
\hline & $\mathrm{R} \$ / \mathrm{ha}$ & $\%$ \\
\hline $\begin{array}{l}\text { Calagem }^{2} \\
\text { Limestone spreading }\end{array}$ & 45,97 & 2,68 \\
\hline $\begin{array}{l}\text { Sementes } \\
\text { Seeds }\end{array}$ & 195,20 & 11,40 \\
\hline \multicolumn{3}{|l|}{$\begin{array}{l}\text { Adubação } \\
\text { Fertilization }\end{array}$} \\
\hline $\begin{array}{l}\text { Plantio (350 kg 10-18-20) } \\
\text { Cropping }\end{array}$ & 363,23 & 21,21 \\
\hline $\begin{array}{l}\text { Cobertura (200 kg 45-00-00) } \\
\text { Top spreading }\end{array}$ & 220,31 & 12,86 \\
\hline \multicolumn{3}{|l|}{$\begin{array}{l}\text { Controle plantas daninhas } \\
\text { Weed control }\end{array}$} \\
\hline $\begin{array}{l}\text { Herbicida pós-emergente } \\
\text { Postemergent herbicid }\end{array}$ & 99,05 & 5,78 \\
\hline \multicolumn{3}{|l|}{$\begin{array}{l}\text { Controle de pragas } \\
\text { Insect control }\end{array}$} \\
\hline $\begin{array}{l}\text { Inseticida } \\
\text { Insecticide }\end{array}$ & 77,49 & 4,52 \\
\hline $\begin{array}{l}\text { Isca formicida } \\
\text { Ant bait }\end{array}$ & 7,50 & 0,44 \\
\hline \multicolumn{3}{|l|}{$\begin{array}{l}\text { Confecção da silagem } \\
\text { Silage making }\end{array}$} \\
\hline $\begin{array}{l}\text { Corte e colheita } \\
\text { Cutting and harvesting }\end{array}$ & 170,23 & 9,94 \\
\hline $\begin{array}{l}\text { Transporte } \\
\text { Transportation }\end{array}$ & 153,51 & 8,96 \\
\hline $\begin{array}{l}\text { Compactação } \\
\text { Compactation }\end{array}$ & 185,19 & 10,81 \\
\hline $\begin{array}{l}\text { Lona ( } 200 \text { micras }) \\
\text { Canvas ( } 200 \text { micra })\end{array}$ & 112,50 & 6,57 \\
\hline Subtotal (A) & $1.630,17$ & 95,18 \\
\hline \multicolumn{3}{|l|}{$\begin{array}{l}\text { Custo de oportunidade } \\
\text { Opportunity cost }\end{array}$} \\
\hline $\begin{array}{l}\text { Terra } \\
\text { Land }\end{array}$ & 50,00 & 2,92 \\
\hline $\begin{array}{l}\text { Capital investido } \\
\text { Invested capital }\end{array}$ & 32,60 & $1,90]$ \\
\hline Subtotal (B) & 82,60 & 4,82 \\
\hline TOTAL $(\mathrm{A}+\mathrm{B})$ & $1.712,77$ & 100,00 \\
\hline $\begin{array}{l}\text { MS silagem }(\%)^{4} \\
\text { Silage DM }\end{array}$ & 31,15 & \\
\hline $\begin{array}{l}\text { Produção silagem, t MS/ha } \\
\text { Silage production, } t \mathrm{DM} / \mathrm{ha}\end{array}$ & 13,184 & \\
\hline $\begin{array}{l}\text { Custo/t MV silagem, } \mathrm{R} \$^{5} \\
\text { Cost/t GM silage, } R \$\end{array}$ & 40,47 & \\
\hline $\begin{array}{l}\text { Custo/t MS silagem, R\$ } \\
\text { Cost/t DM silage, } R \$\end{array}$ & 129,91 & \\
\hline \multicolumn{3}{|c|}{ 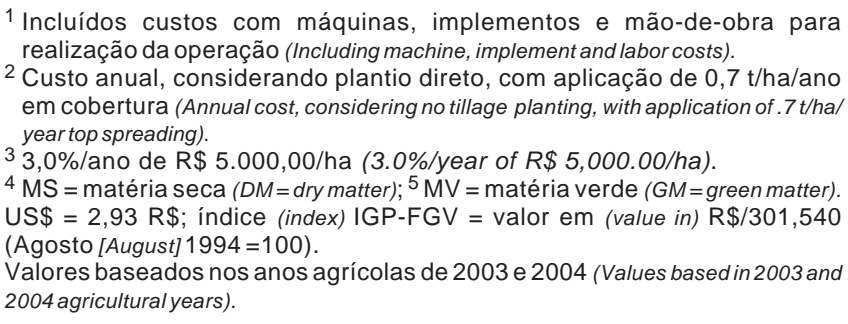 } \\
\hline
\end{tabular}


plantio (21,21\%), adubação de cobertura (12,86\%), sementes (11,40\%), controle de plantas daninhas (5,78\%) e controle de pragas (4,52\%). Nota-se que os componentes sementes e adubação de cobertura apresentaram participação percentual muito próxima no custo total de produção/ha.

Em outros estudos para análise da economicidade de sistemas de alimentação na produção de bovinos de corte (Restle et al., 1998; Restle et al., 1999; Restle et al., 2000 b; Soares et al., 2001; Alves Filho et al., 2003), a adubação representou o maior percentual de participação no custo total, o que justifica os comentários de Pacheco et al. (2006) de que, para reduzir o custo total, esses insumos devem ser adquiridos estrategicamente a preços reduzidos, como por exemplo, compra de grande quantidade ou, dependendo da região em certas épocas do ano, aproveitando os preços de oportunidade. Estratégia desaconselhável seria optar pela redução na quantidade a ser empregada na lavoura ou a utilização de sementes com potencial genético inferior (de menor custo), pois, se os rendimentos de massa verde ou de matéria seca forem baixos no momento da colheita, o custo de produção aumenta.

O componente custos de oportunidade representou $4,82 \%$ do custo total/ha, pouco expressivo se comparado às operações de confecção de silagem (corte e colheita, transporte, compactação e lona), responsáveis por 36,3\% do custo total de R\$1.712,77/ha.

Houve alteração na composição percentual dos ingredientes do concentrado a partir dos 64 dias de alimentação (Tabela 2), visando corrigir as exigências nutricionais dos animais para manter o ganho de peso diário proposto em $1,2 \mathrm{~kg} /$ animal. No entanto, a relação volumoso:concentrado permaneceu constante $(56,21: 43,79)$. Conforme apresentado na Tabela 2, a fração volumoso representou 25,98 e $23,57 \%$ e a fração concentrado, 74,02 e $76,43 \%$ do custo total de cada kg de MS da dieta oferecida aos animais, respectivamente, nos períodos de alimentação 0-63 e 64-147 dias.

Tabela 2 - Demonstração do custo da dieta experimental (volumoso mais concentrado) em diferentes períodos de alimentação Table 2 - Experimental diet cost (forage plus concentrate) in different feeding periods

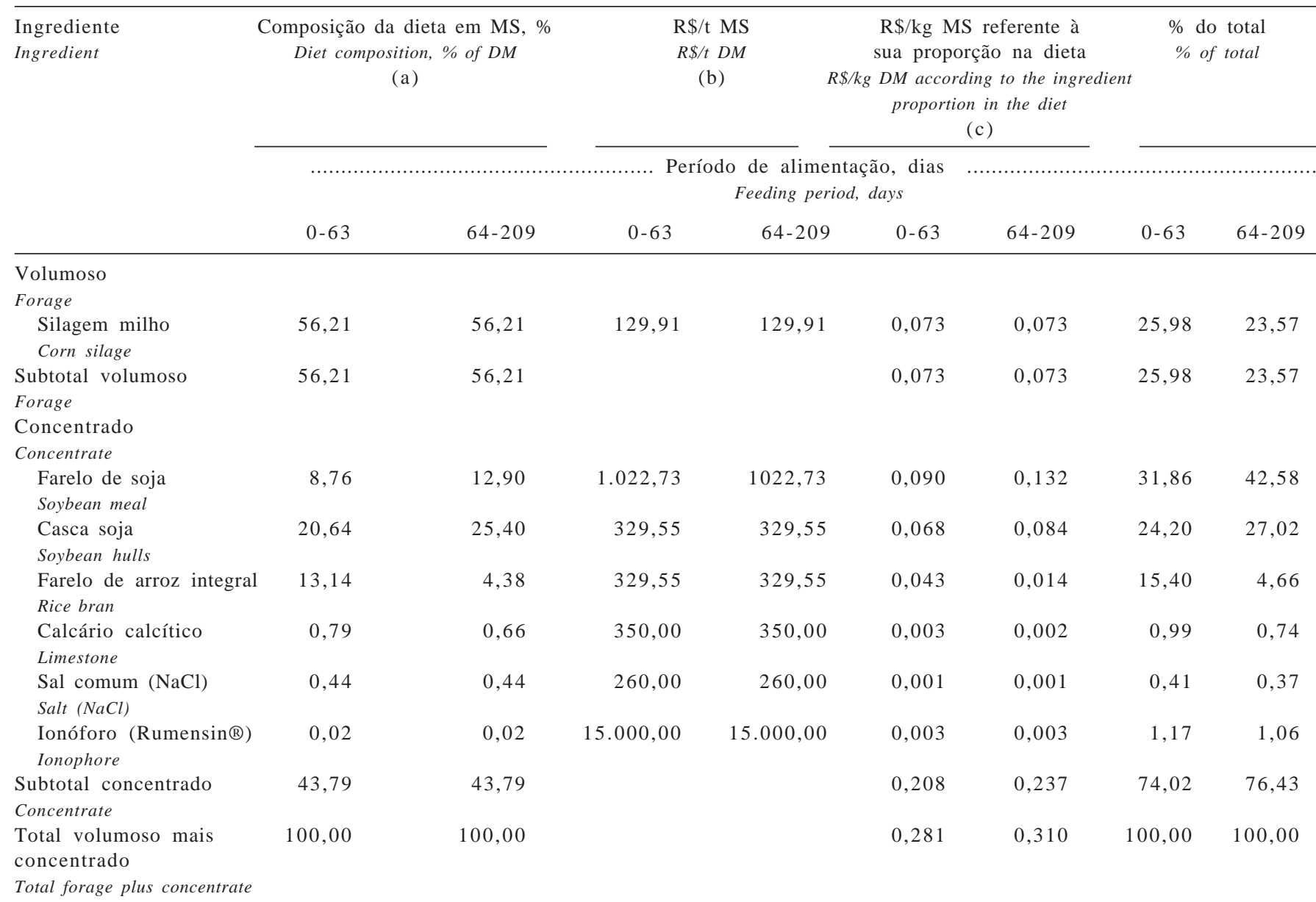

(c) $=[(\mathrm{b}) / 1000] *[(\mathrm{a}) / 100]$.

US\$ = 2,93 R\$; índice (index) IGP-FGV = valor em (value in) R $\$ / 301,540$ (Agosto [August] 1994=100).

Valores baseados nos anos agrícolas de 2003 e 2004 (Values based in 2003 and 2004 agricultural years). 
Trabalhando com novilhos superjovens mestiços Charolês x Nelore terminados em confinamento por 147 dias alimentados com dieta com relação volumoso:concentrado de 60:40, Pacheco et al. (2006) verificaram participação de $76,25 \%$ do componente concentrado e $23,75 \%$ do volumoso, valores próximos ao verificado neste estudo. Portanto, a redução do custo com a dieta a ser oferecida aos animais poderia ser possível com a compra dos ingredientes do concentrado a valores reduzidos, aproveitando preços de oportunidade de acordo com a região.

Na Tabela 3 constam os valores médios referentes a algumas características de desempenho e da carcaça dos animais obtidas de Costa et al. (2002 a,b), utilizadas neste estudo para determinação de algumas características econômicas.

Na Tabela 4, constam os custos totais com alimento (volumoso e concentrado), confecção e fornecimento da alimentação, controle sanitário e compra do animal, gerando o custo subtotal 1 .
O custo de oportunidade do capital investido e do capital de giro (Tabela 5) foram os de maior representatividade no custo subtotal 2 , uma vez que o custo de oportunidade da terra foi calculado sobre a área ocupada pelo animal no confinamento, ou seja, 0,001 ha/animal.

Na Tabela 6 constam o custo total, o custo total subtraído do custo de aquisição do animal, o ganho de peso total, o custo por kg de ganho de peso (CUSTO/ GANHO) e o ganho de peso necessário para cobrir o custo diário.

O CUSTO/GANHO aumentou linearmente com o incremento no peso de abate dos animais, assim como o ganho de peso necessário para cobrir o custo diário. Esse resultado foi reflexo do decréscimo no ganho de peso médio diário com o aumento no peso de abate dos animais (Tabela 3), apesar da alteração percentual dos ingredientes do concentrado, tornando a variação no ganho de peso total menor (61\% dos 340 para os $434 \mathrm{~kg}$ ) que a variação no custo total - G (94\% dos 340 para os $434 \mathrm{~kg}$ ).

Tabela 3 - Médias para características de desempenho e da carcaça de novilhos Red Angus superjovens de diferentes pesos de abate ${ }^{1}$ Table 3 - Means for performance and carcass characteristics of Red Angus young steers according to slaughter weight ${ }^{1}$

\begin{tabular}{|c|c|c|c|c|}
\hline \multirow[t]{2}{*}{$\begin{array}{l}\text { Variável } \\
\text { Item }\end{array}$} & \multicolumn{4}{|c|}{$\begin{array}{l}\text { Peso de abate, kg } \\
\text { Slaughter weight }\end{array}$} \\
\hline & 340 & 373 & 401 & 434 \\
\hline Período de alimentação, dias (Feeding period, days) & 114 & 144 & 168 & 209 \\
\hline Idade, meses (Age, months) & 12,0 & 13,0 & 14,0 & 15,0 \\
\hline Peso de carcaça fria, kg (Cold carcass weight, kg) & 182 & 203 & 212 & 239 \\
\hline Espessura de gordura subcutânea, mm (Subcutaneous fat thickness, mm) & 3,9 & 6,2 & 6,2 & 9,6 \\
\hline Ganho de peso médio diário, kg/animal (Average daily weight gain, kg/animal) & 1,32 & 1,27 & 1,23 & 1,15 \\
\hline CMS diário de volumoso, kg (Forage DMI, kg/day) & 3,77 & 3,82 & 3,85 & 3,90 \\
\hline CMS diário de concentrado, kg (Concentrate DMI, kg/day) & 2,93 & 2,98 & 3,00 & 3,04 \\
\hline CMS total de volumoso, kg (Total forage DMI, kg) & 429,33 & 550,41 & 646,86 & 815,30 \\
\hline CMS total de concentrado, $\mathrm{kg}$ (Total concentrate DMI, kg) & 334,47 & 428,79 & 503,94 & 635,16 \\
\hline Conversão alimentar (Feed conversion) & 5,09 & 5,35 & 5,55 & 6,04 \\
\hline
\end{tabular}

1 Obtido de (Obtained from) Costa et al. (2002 a,b).

Tabela 4 - Médias por animal para custos totais com volumoso, concentrado, confecção do concentrado, fornecimento da alimentação, controle sanitário e compra do animal

Table 4 - Means per animal for total cost with forage, concentrate, concentrate making, feeding supply, health control and animal acquisition

\begin{tabular}{|c|c|c|c|c|}
\hline \multirow[t]{2}{*}{$\begin{array}{l}\text { Variável } \\
\text { Item }\end{array}$} & \multicolumn{4}{|c|}{$\begin{array}{l}\text { Peso de abate, kg } \\
\text { Slaughter weight }\end{array}$} \\
\hline & 340 & 373 & 401 & 434 \\
\hline Custo total com volumoso, $\mathrm{R} \$$ (Total forage cost, $R \$$ ) & 55,81 & 71,55 & 84,08 & 105,98 \\
\hline Custo total com concentrado, $\mathrm{R} \$$ (Total concentrate cost, $R \$$ ) & 168,73 & 219,54 & 260,08 & 330,86 \\
\hline Custo total com confecção do concentrado (C), $\mathrm{R} \$$ (Total concentrate making cost [C], $R \$$ ) & 17,43 & 22,35 & 26,27 & 33,10 \\
\hline Custo total com fornecimento alimentação (D), R\$ (Total feeding supply cost [D], R\$) & 29,37 & 37,09 & 43,28 & 53,84 \\
\hline Custo total com instalações confinamento (E), R\$ (Total feedlot facilities cost $[E], R \$$ ) & 5,90 & 7,45 & 8,69 & 10,81 \\
\hline Custo total com controle sanitário (F), $\mathrm{R} \$$ (Total health control cost $[\mathrm{F}], R \$$ ) & 2,13 & 2,13 & 2,13 & 2,13 \\
\hline Custo total com compra do animal (G), $\mathrm{R} \$^{1}$ (Total animal acquisition cost [G], $R \$^{1}$ ) & 340,20 & 342,00 & 338,40 & 338,40 \\
\hline Custo subtotal 1 (Subtotal cost 1) $(A+B+C+D+E+F+G), R \$$ & 619,57 & 702,11 & 762,93 & 875,12 \\
\hline
\end{tabular}

${ }^{1} \mathrm{~kg}$ boi magro (value per $\mathrm{kg}$ of animal acquisition) $=\mathrm{R} \$ 1,80$.

US\$ = 2,93 R\$; índice (index) IGP-FGV = valor em (value in) R $\$ / 301,540$ (Agosto [August] $1994=100$ ). 
Tabela 5 - Médias por animal para custos de oportunidade da terra e do capital investido

Table 5 - Means per animal for opportunity costs of land and invested capital

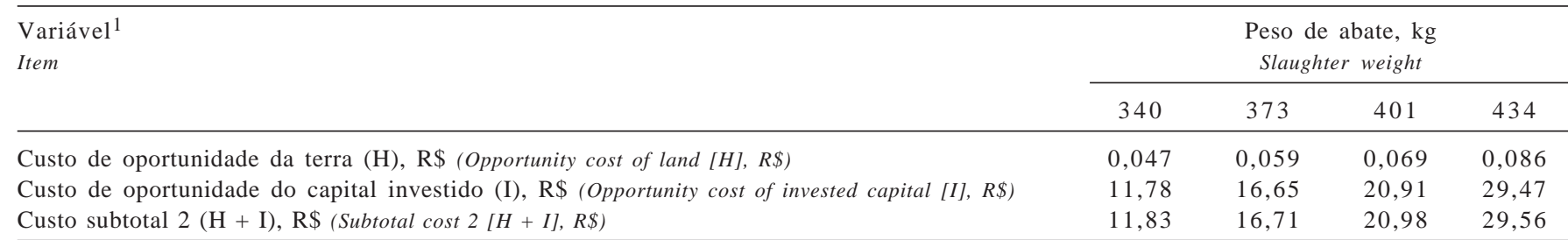

${ }^{1}$ Durante o período de confinamento (During feedlot period).

US\$ = 2,93 R\$; índice (index) IGP-FGV = valor em (value in) R\$/301,540 (Agosto [August] $1994=100$ ).

Tabela 6 - Médias por animal para custo total, ganho de peso total, custo por kg de ganho de peso (CUSTO/GANHO) e ganho de peso necessário para cobrir custo diário de novilhos Red Angus superjovens abatidos com diferentes pesos

Table 6 - Means per animal for total cost, total weight gain, cost per $\mathrm{kg}$ of weight gain (COST/GAIN) and weight gain necessary to cover daily cost of Red Angus young steers according to slaughter weight

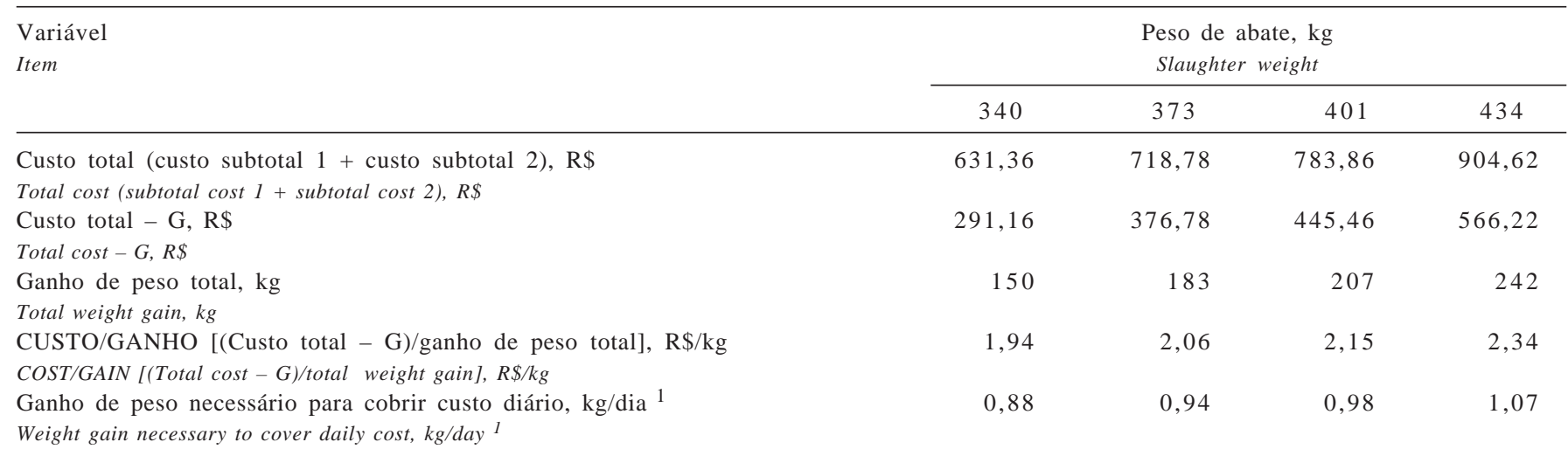

${ }_{1}^{1}$ (CUSTO/GANHO)/preço kg boi gordo, considerando R $\$ 2,20 / \mathrm{kg}$ boi gordo [(COST/GAIN)/price $\mathrm{kg}$ fat beef, considering $R \$ 2.20 / \mathrm{kg}$ fat beef].

US\$ = 2,93 R\$; índice (index) IGP-FGV = valor em (value in) R \$/301,540 (Agosto [August] $1994=100$ ).

Considerando o peso mínimo de carcaça para machos jovens exigido pelos frigoríficos da Região Sul, sem deságio no valor a ser pago ao produtor (180-190 kg, 12-13@, Tabela 3), este valor seria obtido com o abate dos animais aos $340 \mathrm{~kg}$, justamente o menor CUSTO/GANHO $(\mathrm{R} \$ / \mathrm{kg} 1,94)$. Para o peso de carcaça de 230 a $240 \mathrm{~kg}$ (15-16@, Tabela 3) obtido com o peso de abate de 434 kg, além do excesso no grau de acabamento das carcaças, representado pela espessura de gordura subcutânea (9,6 mm, Tabela 3), este seria o peso de abate de maior CUSTO/GANHO para o produtor (R $\$ / k g$ 2,34).

De acordo com a compilação dos diversos componentes de custo apresentados nas Tabelas anteriores, verifica-se na Tabela 7 que o total de volumoso + concentrado foi o componente de maior representatividade quando expresso em relação ao custo parcial (custo total - custo de compra do animal), sendo o concentrado a fração de maior participação.

Restle \& Vaz (1999), Vaz et al. (2000) e Pacheco et al. (2006) afirmaram que, em sistemas de terminação de bovinos de corte em confinamento, os maiores gastos são decorrentes da alimentação dos animais e, entre os componentes da alimentação, o concentrado é o mais oneroso. Portanto, uma alternativa importante para reduzir os custos com alimentação seria o uso de volumosos de qualidade para substituir parte dos nutrientes fornecidos pelo concentrado, porém, sem prejudicar de forma significativa o desempenho dos animais.

Outros custos que tiveram representativa participação no custo parcial foram os de confecção do concentrado, de oportunidade do capital investido e de fornecimento da alimentação. Segundo Pacheco et al. (2006), espera-se grande variação no fornecimento da alimentação, pois a quantidade fornecida está relacionada à dimensão dos cochos, que determina o número de fornecimentos diários. Assim, em virtude da importância de sua participação nos custos de produção, sugere-se o planejamento prévio das instalações objetivando maximização técnica e econômica desta operação.

Considerando a participação dos componentes dos custos relativos ao custo total, o custo com compra do animal foi o mais representativo para os pesos de abate 
Tabela 7 - Médias por animal para custo parcial e total e demais componentes do custo expressos em relação ao custo parcial e ao custo total

Table 7 - Means per animal for partial and total cost and remaining components of cost expressed as proportion of partial cost and total cost

\begin{tabular}{|c|c|c|c|c|c|}
\hline \multirow[t]{2}{*}{$\begin{array}{l}\text { Descrição do custo } \\
\text { Cost description }\end{array}$} & \multicolumn{4}{|c|}{$\begin{array}{l}\text { Peso de abate, kg } \\
\text { Slaughter weight }\end{array}$} & \multirow[t]{2}{*}{$\begin{array}{l}\text { Média } \\
\text { Mean }\end{array}$} \\
\hline & 340 & 373 & 401 & 434 & \\
\hline & & $\cdots$ & $\ldots . \mathrm{R} \$$ & & \\
\hline \multirow{3}{*}{$\begin{array}{l}\text { Parcial } \text { (Partial) }^{1} \\
\text { Total }\end{array}$} & 291,16 & 376,78 & 445,46 & 566,22 & 419,90 \\
\hline & 631,36 & 718,78 & 783,86 & 904,62 & 759,65 \\
\hline & & $\begin{array}{r}\% \text { do c...\% of } \\
\%\end{array}$ & $\begin{array}{l}\text { to parcial }( \\
\text { rtial cost (\%) }\end{array}$ & $\begin{array}{l}\text { lo custo to } \\
\text { total cost) }\end{array}$ & \\
\hline \multirow[t]{2}{*}{ Total com volumoso (Total forage cost) } & 19,2 & 19,0 & 18,9 & 18,7 & 18,9 \\
\hline & $(8,8)$ & $(10,0)$ & $(10,7)$ & $(11,7)$ & $(10,3)$ \\
\hline \multirow[t]{2}{*}{ Total com concentrado (Total concentrate cost) } & 58,0 & 58,3 & 58,4 & 58,4 & 58,3 \\
\hline & $(26,7)$ & $(30,5)$ & $(33,2)$ & $(36,6)$ & $(31,8)$ \\
\hline \multirow{2}{*}{ Total volumoso + concentrado (Total forage + concentrate cost) } & 77,1 & 77,3 & 77,3 & 77,2 & 77,2 \\
\hline & $(35,6)$ & $(40,5)$ & $(43,9)$ & $(48,3)$ & $(42,1)$ \\
\hline \multirow[t]{2}{*}{ Total com confecção concentrado (Total concentrate making cost) } & 6,0 & 5,9 & 5,9 & 5,8 & 5,9 \\
\hline & $(2,8)$ & $(3,1)$ & $(3,4)$ & $(3,7)$ & $(3,2)$ \\
\hline \multirow[t]{2}{*}{ Total com fornecimento alimentação (Total feeding supply cost) } & 10,1 & 9,8 & 9,7 & 9,5 & 9,8 \\
\hline & $(4,7)$ & $(5,2)$ & $(5,5)$ & $(6,0)$ & $(5,3)$ \\
\hline \multirow[t]{2}{*}{ Total com instalações do confinamento (Total feedlot facilities cost) } & 2,0 & 2,0 & 2,0 & 1,9 & 2,0 \\
\hline & $(0,9)$ & $(1,0)$ & $(1,1)$ & $(1,2)$ & $(1,1)$ \\
\hline \multirow[t]{2}{*}{ Total com controle sanitário (Total health control cost) } & 0,7 & 0,6 & 0,5 & 0,4 & 0,5 \\
\hline & $(0,3)$ & $(0,3)$ & $(0,3)$ & $(0,2)$ & $(0,3)$ \\
\hline \multirow[t]{2}{*}{ Total com compra do animal (Total animal acquisition cost) } & - & - & - & - & - \\
\hline & $(53,9)$ & $(47,6)$ & $(43,2)$ & $(37,4)$ & $(45,5)$ \\
\hline \multirow[t]{2}{*}{ Oportunidade da terra (Land opportunity cost) } & 0,016 & 0,016 & 0,015 & 0,015 & 0,016 \\
\hline & $(0,007)$ & $(0,008)$ & $(0,009)$ & $(0,010)$ & $(0,008)$ \\
\hline \multirow[t]{2}{*}{ Oportunidade do capital investido (Opportunity of invested capital cost) } & 4,047 & 4,418 & 4,694 & 5,205 & 4,591 \\
\hline & $(1,866)$ & $(2,316)$ & $(2,667)$ & $(3,258)$ & $(2,527)$ \\
\hline \multirow[t]{2}{*}{ Total com oportunidade (Total opportunity costs) ${ }^{2}$} & 4,063 & 4,434 & 4,709 & 5,220 & 4,607 \\
\hline & $(1,874)$ & $(2,324)$ & $(2,676)$ & $(3,267)$ & $(2,535)$ \\
\hline
\end{tabular}

${ }^{1}$ Custo total - custo com compra do animal (total cost - cost with animal acquisition).

${ }^{2}$ Apenas para período de confinamento (only feedlot period).

entre 340 e $373 \mathrm{~kg}$ e, a partir dos $401 \mathrm{~kg}$, foi superado pelo custo com volumoso + concentrado.

Na Tabela 8 constam as médias para receitas brutas, receitas líquidas e lucratividades obtidas com os diferentes pesos de abate.

Considerando o retorno com a alteração nos preços do boi gordo ( $\mathrm{R} \$ 2,20 / \mathrm{kg}$ ) e do boi magro ( $\mathrm{R} \$ 1,80 / \mathrm{kg}$ ) para o mesmo peso ao início do confinamento, denominado por Restle et al. (2000 a) receita bruta com transferência, verifica-se que neste estudo esta alteração representou R \$ 75,20 a R \$ 76,00 da receita bruta com a venda do animal gordo. Entretanto, esses autores alertaram que, em sistemas de produção de bovinos de corte envolvendo terminação em confinamento, deve-se buscar o máximo de ganho direto (neste estudo receita líquida total), pois o ganho indireto (receita bruta com transferência) nem sempre ocorre.

Analisando a receita líquida total, a lucratividade total e a lucratividade mensal, verificou-se redução acentuada e linear com o incremento no peso de abate dos animais. Dos 340 aos $434 \mathrm{~kg}$ de peso de abate, a lucratividade total reduziu $71 \%$ e a mensal durante o período de confinamento, $84 \%$. Essas perdas foram muito significativas e podem inviabilizar o sistema de terminação de animais mais pesados caso ocorram pequenas reduções no valor da arroba, do dólar ou incrementos nos custos de aquisição de insumos (Pacheco et al., 2006).

Na Tabela 9 verifica-se que o incremento do peso de abate de 340 para $434 \mathrm{~kg}$ resultou em redução de $47 \%$ no número total de animais possíveis de serem alimentados em confinamento/ha (29,79 vs 15,91, respectivamente). A receita líquida com a venda dos animais gordos/ha aos $434 \mathrm{~kg}$ correspondeu a $19 \%$ da obtida com o abate dos animais aos $340 \mathrm{~kg}$ (R \$ 670,77/ha vs R \$ 3475,09/ha).

A manutenção de animais até atingirem peso de abate de $401 \mathrm{~kg}$ promoveu lucratividade (\%/ha) de 0,83 para o período de lavoura + confinamento e lucratividade mensal para 12 meses (V) (\%/ha), superior à remuneração mais conhecida ou difundida, a poupança $(6,0 \%$ ao ano ou 0,50\% ao mês). 
Tabela 8 - Médias por animal para receita bruta com venda do animal gordo e com transferência, receita líquida total, lucratividade total e mensal do confinamento de novilhos Red Angus superjovens abatidos com diferentes pesos

Table 8 - Means per animal for gross income with sale of finished animal and with transfer, total net income, total and monthly profitability of Red Angus young steers according to slaughter weight

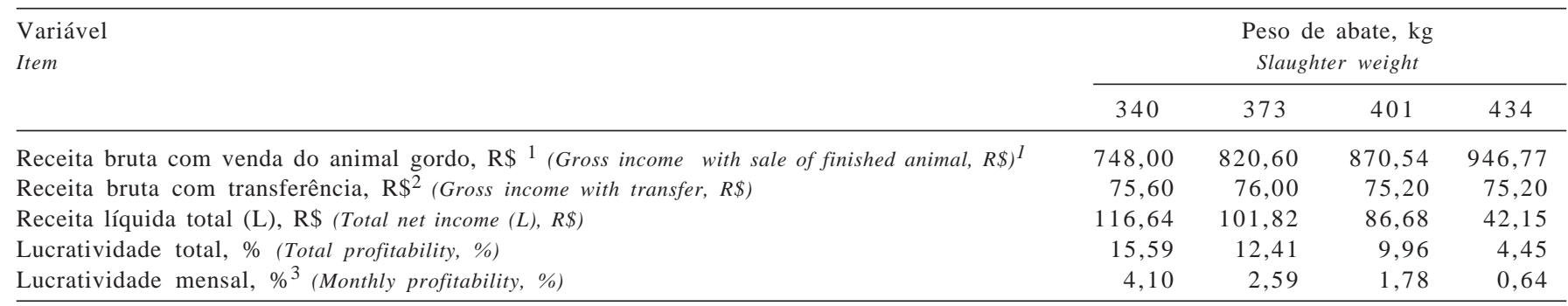

$1 \mathrm{~kg}$ boi gordo ( $\mathrm{kg}$ fat beef cattle) $=\mathrm{R} \$ 2,20$.

2 Fonte (Source): Restle et al. (2000 a).

${ }^{3}$ Apenas durante o período de confinamento (Only during feedlot period).

US\$ = 2,93 R\$; índice (index) IGP-FGV = valor em (value in) R\$/301,540 (Agosto [August] $1994=100$ ).

Tabela 9 - Médias para área necessária de confinamento e de lavoura, área total, animais possíveis de serem alimentados em confinamento/ha, receita líquida com venda dos animais gordos, período de lavoura + confinamento e lucratividades do confinamento de novilhos Red Angus superjovens abatidos com diferentes pesos

Table 9 - Means for area necessary for confinement and crop, total area, possible animals of being feeding in feedlot/ha, net income with sale of finished animals, crop plus confinement periods and monthly profitability of Red Angus young steers according to slaughter weight

\begin{tabular}{|c|c|c|c|c|}
\hline \multirow[t]{2}{*}{$\begin{array}{l}\text { Variável } \\
\text { Item }\end{array}$} & \multicolumn{4}{|c|}{$\begin{array}{l}\text { Peso de abate, kg } \\
\text { Slaughter weight }\end{array}$} \\
\hline & 340 & 373 & 401 & 434 \\
\hline Área necessária de confinamento (O), ha/animal (Area necessary for feedlot [O], ha/animal) & 0,001 & 0,001 & 0,001 & 0,001 \\
\hline Área necessária de lavoura (P), ha/animal ${ }^{1}$ (Area necessary for crop [P], ha/animal) & 0,033 & 0,042 & 0,049 & 0,062 \\
\hline Área necessária total (Q), ha/animal (Total area [Q], ha/animal) & 0,034 & 0,043 & 0,050 & 0,063 \\
\hline Animais possíveis de serem alimentados em confinamento/ha (R) (Feedlot capacity/ha $[R]$ ) & 29,79 & 23,39 & 19,97 & 15,91 \\
\hline Receita líquida com venda dos animais gordos (S) (Net income with sale of finished animals), R\$/ha & $3.475,09$ & $2.381,94$ & $1.731,49$ & 670,77 \\
\hline Período lavoura + confinamento $(\mathrm{T})$, meses (Crop plus confinement periods [T], months) & 7,80 & 8,80 & 9,60 & 10,97 \\
\hline Lucratividade mensal para T (U), \%/ha (Monthly profitability for $T[U], \% / h a)$ & 2,00 & 1,41 & 1,04 & 0,41 \\
\hline Lucratividade mensal para 12 meses (V), \%/ha (Monthly profitability for 12 months [V], \%/ha) & 1,30 & 1,03 & 0,83 & 0,37 \\
\hline
\end{tabular}

1 De acordo com o consumo de volumoso (According to forage intake).

$\mathrm{Q}=\mathrm{O}+\mathrm{P} ; \quad \mathrm{R}=1 \mathrm{ha} / \mathrm{Q} ; \quad \mathrm{S}=\mathrm{R}$ * $\mathrm{L} ; \quad=(\mathrm{T}$ * $\mathrm{U}) / 12$.

US\$ = 2,93 R\$; índice (index) IGP-FGV = valor em (value in) R $\$ / 301,540$ (Agosto [August] $1994=100$ ).

Os resultados obtidos neste estudo corroboram os descritos por Pacheco et al. (2006), que, em estudo para avaliação da economicidade da terminação em confinamento de novilhos mestiços Charolês $\times$ Nelore jovens e superjovens, verificaram que o incremento no período de alimentação promoveu redução na lucratividade desse sistema de terminação, proporcionando resultados mais favoráveis para a terminação de novilhos jovens com 22,8 meses de idade (34 dias de alimentação), seguido pelos superjovens com 12,4 meses de idade (84 dias de alimentação) e com 15,2 meses de idade (143 dias de alimentação).

\section{Conclusões}

Na formação e condução da lavoura, as operações mais representativas do custo total foram adubação de plantio, adubação de cobertura, sementes, controle de plantas daninhas e de pragas.
A alimentação com volumoso mais concentrado foi o componente de maior representatividade nos custos quando desconsiderado o custo de compra do animal. Entre os componentes da alimentação, o mais oneroso foi o concentrado. O incremento de 340 para $434 \mathrm{~kg}$ no peso de abate reduziu a lucratividade da terminação em confinamento de novilhos Red Angus superjovens.

Considerando a variabilidade do potencial genético para desempenho dentro de uma mesma raça, é importante a escolha rigorosa dos animais em sistemas de terminação em confinamento.

\section{Literatura Citada}

ALVES FILHO, D.C.; NEUMANN, M.; RESTLE, J. et al. Características agronômicas produtivas, qualidade e custo de produção de forragem em pastagem de azevém (Lollium multiflorum Lam) fertilizada com dois tipos de adubo. Ciência Rural, v.33, n.1, p.143-149, 2003. 
COSTA, E.C.; RESTLE, J.; PASCOAL, L.L. et al. Desempenho de novilhos Red Angus superprecoces, confinados e abatidos com diferentes pesos. Revista Brasileira de Zootecnia, v.31, n.1, p.129-138, 2002a.

COSTA, E.C.; RESTLE, J.; VAZ, F.N. et al. Características da carcaça de novilhos Red Angus superprecoces abatidos com diferentes pesos. Revista Brasileira de Zootecnia, v.31, n.1, p.119128, 2002b.

MOREnO, J.A. Clima do Rio Grande do Sul. Porto Alegre: Secretaria da Agricultura, 1961. 41p.

NATIONAL RESEARCH COUNCIL - NRC. Nutrient requirements of domestic animals. 6.ed. Washington, D.C.: National Academy Press, 1984. 90p.

RESTLE, J.; LUPATINI, G.C.; ROSO, C. et al. Eficiência e desempenho de categorias de bovinos de corte em pastagem cultivada. Revista Brasileira de Zootecnia, v.27, n.2, p.397404, 1998.

PACHECO, P.S.; RESTLE, J.; VAZ, F.N. et al. Avaliação econômica da terminação em confinamento de novilhos jovens e superjovens de diferentes grupos genéticos. Revista Brasileira de Zootecnia, v.35, n.1, p.309-320, 2006.

RESTLE, J.; ROSO, C.; SOARES, A.B. Produção animal e retorno econômico em misturas de gramíneas anuais de estação fria. Revista Brasileira de Zootecnia, v.28, n.2, p.235-243, 1999.
RESTLE, J.; ALVES FILHO, D.C.; NEUMANN, M. Eficiência na terminação de bovinos de corte. In: RESTLE, J. (Ed) Eficiência na produção de bovinos de corte. Santa Maria: Universidade Federal de Santa Maria, 2000a. p.277-303.

RESTlE, J.; ROSO, C.; SOARES, A.B. Produtividade animal e retorno econômico em pastagem de aveia preta mais azevém adubada com fontes de nitrogênio em cobertura. Revista Brasileira de Zootecnia, v.29, n.2, p.357-364, 2000b.

RESTLE, J.; VAZ, F.N. Confinamento de bovinos definidos e cruzados. In: LOBATO, J.F.P.; BARCELLOS, J.O.J.; KESSLER, A.M. (Eds.) Produção de bovinos de corte. Porto Alegre: EDIPUCRS, 1999. p.141-198.

SOARES, A.B.; RESTLE, J.; ROSO, C. et al. Dinâmica, qualidade, produção e custo de produção de forragem da mistura aveia preta e azevém anual adubada com diferentes fontes de nitrogênio. Ciência Rural, v.31, n.1, p.117-122, 2001.

VAZ, F.N.; VAZ, R.Z.; ROSO, C. Tipos e níveis de concentrado para o confinamento. In: RESTLE, J. (Ed.) Eficiência na produção de bovinos de corte. Santa Maria: Universidade Federal de Santa Maria, 2000. p.219-257.

Recebido: $15 / 07 / 05$ Aprovado: 22/12/06 